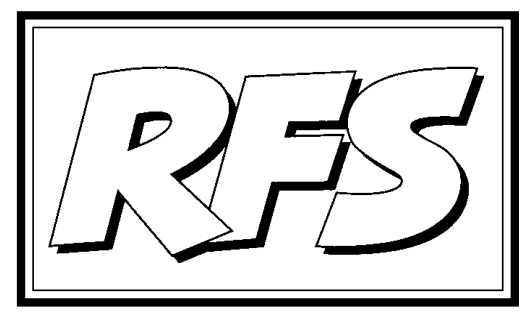

Revista de Fomento Social, 55 (2000), 311-339

\title{
En torno a la crisis de Manos Unidas
}

\section{Consejo de Redacción}

La Organización No Gubernamental para el Desarrollo (ONGD) católica Manos Unidas (MU) ha sufrido en los últimos meses la crisis más grave de toda su historia. Como probablemente conocen nuestros lectores, se trata de un conflicto habido entre los dirigentes de la citada organización y la jerarquía eclesiástica, de la que depende como organización católica. Este conflicto cuyos orígenes se remontan años atrás- ha desembocado en importantes decisiones que, mucho nos tememos, marcarán de forma irreversible tanto la propia marcha de la organización, como su papel en la batalla contra el hambre y la pobreza en el mundo y la forma de abordarla desde una perspectiva a la vez cristiana y competente en su ámbito.

El Consejo de Redacción de la Revista de Fomento Social decidió abordar el análisis del conflicto por dos motivos diferentes: por las relaciones mantenidas con el mundo de la cooperación al desarrollo y con las organizaciones que actúan en ese campo y por el alcance y trascendencia de los problemas que se han suscitado.

En efecto, desde hace muchos años conocemos a MU -entre otras ONGD- y 
hemos colaborado con ella a diferentes niveles ${ }^{1}$. En algunas ocasiones hemos discrepado quizás de algunas de sus actuaciones ( ise trata siempre de asuntos complejos y opinables!), menos por cierto que de las de otras ONGD que han pululado últimamente en nuestro horizonte español e internacional y en las que -incluso en algunas supuestamente confesionales- "no es oro todo lo que reluce". Hemos seguido de cerca los acontecimientos y hemos asistido con dolor al desenlace. Sabemos que el ambiente ha estado muy enrarecido y que muchas personas afectadas están perplejas, desconcertadas y, desde luego, desmoralizadas.

Pero nos ha movido también a reflexionar sobre esta situación tan delicada el convencimiento de que el asunto desborda con mucho la simple anécdota. Intuimos en lo ocurrido un significativo exponente de profundos problemas que atañen tanto a la manera de concebir la Iglesia y la acción del cristiano laico en la sociedad, como a la ingente y nada fácil tarea de la lucha organizada contra el subdesarrollo y la miseria en el mundo.

Las páginas que siguen tienen un doble objetivo: proporcionar, avalados por nuestra propia experiencia y la reflexión derivada de ella, elementos de juicio sobre un acontecimiento que, nos consta, ha inquietado a muchos de nuestros lectores; participar serena y críticamente en un debate que también a nosotros nos afecta de alguna manera y al que no podemos permanecer ajenos. Queremos abordar el tema con la mejor intención de fidelidad a la verdad y con el máximo respeto a las partes afectadas, a sabiendas de que se trata de un asunto delicado y de que no resulta fácil tomar en consideración todos los elementos en juego. Ofrecemos, pues, nuestras reflexiones como una aportación en el marco de una Iglesia adulta y dialogante, en la que todos tenemos el derecho y la obligación de expresar respetuosamente nuestros puntos de vista $y$, naturalmente, abiertos al diálogo que de estas reflexiones pueda surgir.

Hemos articulado esta reflexión en varios grandes apartados, para los cuales hemos contado con la colaboración de di versos especialistas y testigos directos de los hechos. Comenzamos haciendo una exposición de lo ocurrido, a la luz de la información de que disponemos ( prensa, publicaciones católicas especia-

1 La cooperación al desarrollo es, desde hace años, una de las líneas de actuación institucional de ETEA. Esto significa que un número considerable de sus miembros han trabajado en este terreno y han mantenido relaciones con otras instituciones de actividades semejantes, entre ellas MU. De toda esta experiencia se benefician las páginas que siguen, aunque las posturas que en ellas se toman son de exclusiva responsabilidad del Consejo de Redacción de la Revista. 
lizadas y fuentes directas). A continuación ofrecemos una síntesis de la historia de esta organización y un análisis del papel de MU en el creciente y complejo mundo de las Organizaciones No Gubernamentales para el Desarrollo (ONGD) de nuestro país: ambas cosas pueden ser de interés a la hora de valorar lo sucedido. Por fin abordamos las que consideramos dimensiones más relevantes de la crisis: no sólo los problemas que se han planteado directamente, sino los que pensamos que subyacen a todo el conflicto, que son los de más alcance.

\section{Los hechos}

Los primeros síntomas de desencuentro entre la cúpula de la Conferencia Episcopal Española (CEE) y los dirigentes de MU, que apenas trascendieron a la opinión pública, se sitúan en el periodo de la presidencia de Ana de Felipe (1991-1997). Fue entonces cuando desde la CEE se pidió a MU que destinara parte de sus fondos a proyectos de evangelización explícita. MU se negó a ello y acusó de intervencionismo a la CEE. Quizás la entonces presidenta y la Asamblea de Delegadas no supieron medir las consecuencias de su reacción, la cual ha marcado negativamente todo el proceso, tiñendo de desconfianza las relaciones entre la cúpula episcopal y la propia organización. La siguiente presidenta, Consuelo Lobo, elegida en conti nuidad con la línea de Ana de Felipe, tuvo que negociar con la CEE durante todo su mandato (1997-2000) en un ambiente de mutua desconfianza. Todo ello cristalizó en los dos conflictos concretos que han saltado en estos últimos meses a los medios de comunicación: la intervención de los obispos, primero en la redacción de los nuevos estatutos y después en la elección de la nueva presidenta. Sigue el rela to somero de cómo se desarrollaron estos dos conflictos.

\subsection{La intervención de la CEE en la elaboración de los estatutos}

En octubre de 1997, Mons. Elías Yanes, Presidente de la CEE, comunicó a la entonces presidenta, Consuelo Lobo, la necesidad de proceder a la elaboración de nuevos estatutos dado que el plazo de los vigentes caducaba en febrero de 1998. Se constituyó la correspondiente Comisión de Estatutos en noviembre del mismo año; tras varios meses de trabajo se llegó a un texto consensuado por todas las partes, que se presentó a la CEE.

El 12 de diciembre de 1998 la CEE, a través de su jurista miembro de la Comisión, hizo llegar a MU un nuevo borrador de Estatutos con una serie de modificaciones sustantivas de fondo y forma. Faltaban sólo cuatro días para la 
Asamblea Extraordinaria de MU que tenía que aprobar el texto definitivo. Hubo de suspenderse la aprobación.

Se formó entonces una nueva comisión. El 24 de marzo de 1999 Mons. Juan José Asenjo, Secretario General de la CEE, hace llegar por escrito a MU los criterios compartidos por los obispos en la LXXI Asamblea Plenaria de la CEE para la renovación de sus estatutos: para que la CEE pueda aprobar en su asamblea de noviembre de 1999 los Estatutos, los obispos pedían a MU que clarificara "necesariamente" su identidad como organización de la Iglesia Católica, la formación católica de sus miembros, la intervención de los obispos en la elección de delegados y la participación de los profesionales.

Esta revisión fue elaborada por una Comisión de Estatutos, en la que participaron miembros de MU junto a otros que representaban a la CEE. Estos, según la carta citada de 24 de marzo de 1999, habían de supervisar "el curso de la negociación" y "los aspectos técnicos de los nuevos estatutos". En un ambiente de diálogo y entendimiento se logró consensuar un proyecto en que parecía que se daba respuesta a todas las demandas de los obispos. También en el punto que se convertiría luego en el principal objeto de polémica, el de la participación de los profesionales (arto 12.3), se llegó a una formulación que contó con el apoyo unánime de todos los miembros de dicha comisión y que fue enviado a la CEE el 1 de febrero de 2000. Decía así: "Al ser Manos Unidas una organización de voluntarios (artículo 2.3) , los puestos de responsable de áreas y de departamentos se cubrirán con voluntarios idóneos; sólo cuando ello no resulte posible, a juicio de la Comisión Permanente, podrán ser cubiertos por personas contratadas". Este texto fue aprobado el 14 de marzo de 2000 por la Asamblea Extraordinaria de MU con más de dos tercios de los votos, tal como habían solicitado los obispos: 52 votos a favor; 16 en contra; 1 en blanco ( 2 delegaciones estuvieron ausentes). De esta forma, la asamblea de MU daba cumplimiento a lo indicado por la CEE mediante carta de su Secretario General a MU de fecha 14 de diciembre de 1999 en la que se pedía que "las dos sensibilidades existentes en la asociación deben esforzarse por buscar de mutuo acuerdo una fórmula canónicamente viable y aceptada por todos que pueda alcanzar los 2/3 de los votos de delegadas en una asamblea que se podría celebrar en los próximos meses y en cualquier caso antes de la próxima asamblea plenaria de la CEE".

Sin embargo, poco después Mons. Omella, Presidente del Comité Rector de MU, comunicó en nombre de la CEE que el controvertido artículo había sido ratificado en los términos siguientes: "Al ser Manos Unidas una organización de 
voluntarios ( artículo 2.3) , los puestos de responsable de áreas y de departamentos se cubrirán con voluntarios" ( suprimiéndose todo lo demás). Aunque este hecho fue comunicado semanas antes por Mons. Omella a MU el escrito oficial dirigido a la organización lleva fecha de 16 de mayo. Faltaban sólo nueve días para que la nueva Asamblea de MU conociera los nuevos Estatutos aprobados.

Días antes de la Asamblea del 25 de mayo la presidenta, vicepresidentas, tesorero y dos delegadas miembros del Comité Rector presentaron un recurso ante la CEE por la modificación de los Estatutos que, de diferentes formas, fue apoyado por distintas iniciativas de las delegadas $y$, posteriormente, de otros miembros de MU. El recurso argumentaba básicamente que la CEE se había excedido en sus competencias al aprobar un texto que no había sido refrendado previamente por la institución. Según los propios estatutos de MU lo único que podía hacer la CEE era aprobar o rechazar la propuesta presentada por la organización, pero no modificarla. Sobre este recurso la Comisión Permanente de la CEE del mes de junio remitió una decisión a la asamblea plenaria de los obispos del mes de noviembre próximo.

En la Asamblea del 25 de mayo dimitieron irrevocablemente de sus cargos las tres vicepresidentas (Lola de Mesa, Esther Colmenarejo y Julia Navarro) y el tesorero (J osé Antonio Casaus) por el "desacuerdo, tanto en el fondo como en la forma", con la decisión adoptada por la CEE, en la que se aprobaron los nuevos estatutos de la organización, explica una nota de MU2. Dicha nota añadía:

"La CEE ha modificado sustancialmente la propuesta presentada por Manos Unidas. Ésta había sido elaborada con la participación de la propia CEE y aprobada por más de dos tercios de la Asamblea de delegados y por el Comité Rector de Manos Unidas (ambos compuestos en su totalidad por voluntarios), cumpliendo así las instrucciones dadas previamente por la propia CEE. Se ha decidido por tanto, en contra de la voluntad mayoritaria de la organización, desautorizando a sus órganos de gobierno".

Poco después la presidenta, Consuelo Lobo, convocó anticipadamente elecciones a la presidencia "haciendo suyas las razones que han llevado a estas dimisiones". Media docena de profesionales contratados dejaron ya entonces la organización. Otros tantos lo han hecho después.

2 Para este apartado nos basamos en informaciones directas y en las crónicas siguientes: J. Fernández, "Dimisiones en la cúpula de MU. Convocadas nuevas elecciones para presidente", Vida Nueva ( 3 junio 2000) 12; Alandar (junio 2000), que reproduce el texto literal de la nota de la organización. 
Entre las diversas gestiones que se llevaron a cabo durante estos meses destaca una entrevista entre Mons. Rouco y los responsables de MU celebrada durante el mes de abril, que fue calificada de "muy dura" por testigos directos. En ella el Presidente de la CEE comunicó los cambios introducidos en los estatutos y-siempre según estos testigos- se mostró inflexible con las responsables de la organización, recordándoles su obligación de obedecer, como miembros de un movimiento de laicos sometido a la jerarquía.

El cambio sustancial introducido en los estatutos por la CEE excluye toda presencia de profesionales contratados en puestos directivos o de gestión, de forma que todas las decisiones serán tomadas únicamente por voluntarios. Los estatutos ya establecían claramente la exclusión de los profesionales contratados de cualquier cargo de gobierno, tanto individual (presidenta, vicepresidentas, secretario, tesorero, delegada o vicedelegada) como colegiado (Asamblea y Comisión Permanente, antiguo Comité Rector). Por lo tanto, lo que los obispos han prohibido es tener ninguna responsabilidad en los cargos de gestión, incluidos los de carácter intermedio como eran los coordinadores de departamento.

\subsection{La intervención de la CEE en la elección de nueva presidenta ${ }^{3}$}

La elección de nueva presidenta quedó fijada para el 27 de julio siguiente. Tampoco en este breve intervalo de dos meses faltaron los incidentes, como se recoge a continuación.

De las 11 candidatas para la presidencia que fueron presentadas por las diferentes delegaciones, la CEE vetó a 5. Esta nueva intervención episcopal provocó la dimisión de Consuelo Lobo. Nos consta que no se les ha dado ninguna explicación, aun cuando la han pedido.

Llegada la fecha del 27 de julio, la Asamblea eligió presidenta a Ana Álvarez de Lara, hasta entonces responsable de los proyectos de cooperación de MU en Madagascar y Mozambique. Participaron 63 delegadas - diez de ellas representadas- de las 71 que existen en toda España. La presidenta electa necesitó tres vueltas y aun así sólo logró 24 votos a favor de las 63 delegaciones presentes, aunque se benefició de las 31 abstenciones y los 2 votos en blanco (los restantes votos fueron a otras candidatas). Una nota de la organización señaló que las

3 Tomamos los datos de sendas crónicas de Vida Nueva (29 julio y 5-12 agosto 2000), El País (28/7/2000), y El Diario de Navarra (2/8/2000). 
abstenciones fueron "consecuencia de los continuos desacuerdos entre un sector mayoritario de Manos Unidas y la CEE, ante el veto de la misma a las candidatas propuestas por la mayoría".

Tras la Asamblea, 10 de las 71 delegadas dimitieron, a saber: Alcalá de Henares, Burgos, Cádiz, Ceuta, J erez de la Frontera, Madrid, Murcia, Pontevedra, San Sebastián, y Valencia, a lo que hay que sumar la delegada de Santiago de Compostela. Otras delegaciones, como la de Barcelona, condicionaron su dimisión a la resolución de los recursos presentados a la CEE y "por respeto a los beneficiarios directos de la gestión de Manos Unidas", manifestando el desacuerdo de todos los miembros con el proceso de elección de la nueva presidenta. Las dimisiones se produjeron, según declaración de las personas afectadas, por considerar que la CEE había alterado "radicalmente el proceso electoral de Manos Unidas" y por creer que "no va a ser posible continuar la trayectoria de buen trabajo y eficacia, austeridad y motivación". Algunas dimisionarias aseguraron no estar "en contra de los obispos", pero dijeron sentir que éstos ya no respaldaban su gestión ni la concepción que ellas tenían de MU.

Por su parte, la nueva presidenta sostenía una postura claramente contraria al anterior equipo en los temas más polémicos ${ }^{4}$. Criticó en su programa "la excesiva profesionalización" a la que había llegado MU por "el número excesivo de personas contratadas". A su juicio, ello podía poner en peligro el ideario de la ONG, "una asociación de fieles cristianos unidos por el compromiso cristiano de ayuda a los países desfavorecidos".

\section{Buscando luz en la historia de Manos Unidas}

Llega dos aquí, nos parece o portuno volver la vista atrás y recorrer aunque sea brevemente la historia de la organización.

Como punto de partida puede servirnos esta presentación que aparece en la última Memoria de MU, la de 1999:

“Manos Unidas es una Organización No Gubernamental para el Desarrollo (ONGD) católica, de voluntarios que luchan contra la pobreza, el hambre, la malnutrición, la enfermedad, la falta de instrucción y el subdesarrollo (Estatutos, art.6) y contra sus causas: la injusticia, el desigual reparto de los bienes y las oportunidades entre las personas y los pueblos, la ignorancia, los prejuicios, la insolidaridad, la indiferencia y la crisis de valores humanos y cristianos" 5 .

4 Diario de Navarra, loc. cit. 2 de agosto de 2000.

5 MANOS UNIDAS (1999), Memoria 1999, p. 5 
Tras esta definición se encuentra una organización que, a lo largo de sus más de cuarenta años de existencia, se ha ido adaptando a los nuevos escenarios y desafíos que imponía la cooperación al desarrollo en España. Pero MU es además, por decisión de la CEE, el organismo para la cooperación de la Iglesia española al desarrollo económico y social del tercer mundo ${ }^{6}$. Este doble nivel de su existencia, tan característico de MU, está también en el origen de muchas tensiones a que se ha visto, y sigue viéndose, sometida.

\subsection{Los grandes hitos de la historia de Manos Unidas}

MU tiene su origen en el manifiesto para luchar contra el hambre en el mundo lanzado por las Unión Mundial de Organizaciones Femeninas Católicas (UMOFC). En 1955 la UMOFC decidió que sus afiliadas deberían organizar, en sus respectivos países, acciones encaminadas a mentalizar a la sociedad sobre la situación de los entonces llamados Países en Vías de Desarrollo ${ }^{7}$.

En julio de 1960 este manifiesto fue asumido por la FAO, que ya ese mismo año será quien lance oficialmente la Campaña Mundial Contra el Hambre en el Mundo. En España este lanzamiento es puesto en marcha por la rama femenina de la Acción Católica por su vinculación a la UMOFC como miembro activo, desde ese mismo año 1960. En España la Campaña adoptó el nombre de Manos Unidas, que utilizaría conjuntamente con el de Campaña Contra el Hambre en el Mundo (CCHM) hasta llegar a identificase totalmente entre $s^{8}{ }^{8}$.

Desde esta atención prioritaria al problema del hambre en el mundo, MU entendió siempre sus objetivos de una forma más amplia: como la promoción del hombre a través de obras que fomentan condiciones de vida más dignas.

Pero en la España de aquellos años la cooperación internacional al desarroIlo no encontraba un ambiente propicio como consecuencia de la escasa permisividad hacia el asociacionismo y a cualquier iniciativa social que se

6 Cf. Oficina de Estadística y Sociología de la Iglesia, Guía de la Iglesia Católica en España. Nomenclator 2000, Edice 2000, 268.

7 La mayor parte de los datos obtenidos sobre los orígenes de MU se encuentran recogidos en la tesis doctoral inédita realizada por I. DE FeLIPE BoenTE (1981) El papel del ser humano en la ayuda al desarrollo: las organizaciones no gubernamentales de ayuda al Tercer Mundo.

8 Otras organizaciones internacionales que se sumaron a dicha campaña fueron: MISEREOR en Alemania, Mani Tese en Italia, Oxfam en Inglaterra, Comité Catholique contre la Faim (CCCF) en Francia. 
planteara el tema ${ }^{9}$. En la práctica apenas se podía hacer algo en este terreno si no era al amparo de la Iglesia católica, aprovechando con frecuencia los resquicios que ofrecía el Concordato con la Santa Sede de 1953. Por otra parte, la Iglesia universal conoció en esos mismos años una decidida apertura a los problemas del tercer mundo, de las que son exponentes autorizados las encíclicas Mater et magistra ${ }^{10}$ de J uan XXIII (1961) y Populorum progressio de Pablo VI (1967), además de la constitución Gaudium et spes del Vaticano II (1965).

Especial interés reviste la creación por parte de Pablo VI del Secretariado para la Cooperación Internacional al Desarrollo Socioeconómico, al que se encomendó la aplicación de las enseñanzas y recomendaciones de la Populorum progressio, tanto en la realidad concreta de los países pobres, como en la necesaria transformación de las estructuras socioeconómicas y políticas en las sociedades desarrolladas del Norte. Su existencia corre pareja con la de la Comisión Pontificia Justicia y Paz. ${ }^{11}$

En España el Secretariado de Cooperación al Desarrollo fue puesto en marcha, junto con J usticia y Paz, en 1969, justamente el año en que se consumó la crisis de los movimientos especializados de Acción Católica después de un largo conflicto con la jerarquía, al que nos referiremos luego. En ambas organizaciones encontraron acogida y espacio para actuar muchos antiguos militantes católicos, contribuyendo así a la preparación remota de la futura transición democrática española. Y no faltaron las dificultades en ninguna de las dos, que tenían su origen unas veces en las autoridades políticas y otras en las mismas instancias eclesiales.

El Secretariado de Cooperación al Desarrollo merece una atención especial por la importancia que tuvo en la transformación de las instituciones que se movían en este terreno por aquellos años. Tres características destacan en él:

9 La información puede ampliarse en M. L. ORTEGa CARPIO (1994), Las ONGD en la crisis del desarrollo. ETEA-IEPALA, pp. 144-145.

10 En esta encíclica, Juan XXIII hace un elogio de los católicos de los países más ricos por sus iniciativas y esfuerzos a favor de un desarrollo solidario, a los que dice: "A estos queridos hijos nuestros, que en toda la tierra demuestran claramente la perenne eficacia y vitalidad de la Iglesia con su esfuerzo extraordinario en promover el genuino progreso de las naciones, e inspirar la fuerza saludable de la auténtica civilización, queremos expresar nuestro aplauso y nuestro agradecimiento". Nos parece que este texto muestra bien el clima eclesial en que nacieron proyectos como MU.

11 Populorum Progressio, 5. 
1. Estaba formado por profesionales y técnicos, creyentes o no, especializados en diversos campos relacionados con la cooperación al desarrollo.

2. El Secretariado se propuso cambiar los comportamientos y las concepciones marcadamente asistenciales de las organizaciones de Iglesia por actitudes y prácticas de acción social promocionales y autoorganizativas. Se pretendía corregir concepciones y prácticas de las misiones tradicionales enriqueciéndolas con un concepto integral de cooperación al desarroIlo, con base socioeconómica. Es en ese contexto donde se irán decantando muchos grupos y organizaciones que, posteriormente, integrarían las ONGD de procedencia religiosa. Entre ellas, MU.

3. En relación con su actividad en el tercer mundo, el Secretariado optó por luchar contra las dependencias de todo tipo, prestando su colaboración a los procesos de autodesarrollo que surgían entre los grupos y comunidades de base popular. Su actuación en el primer mundo se orientó, correlativamente, a la denuncia y a la transformación de las mentalidades y de las estructuras de poder económico, político e ideológico.

La vinculación de MU con la Iglesia española se verá directamente afectada por las directrices que emanaron de dicho Secretariado. Ya en 1970 adquiere una adscripción mayor a la Iglesia al acordar la Conferencia Episcopal que en todas las parroquias se hiciera una colecta extraordinaria contra el hambre en el mundo el segundo domingo de febrero, que administraría MU, y convocar el viernes anterior a dicho domingo una jornada de ayuno voluntario. Unos años después, en 1978, la Asamblea Plenaria de la CEE aprueba "Ia erección como persona jurídica de derecho canónico del Comité Católico de la Campaña contra el Hambre, con el nombre de Manos Unidas"12.

Precisamente de estos años, en que la Iglesia está estrechando sus vínculos con MU, proceden los dos testimonios que siguen. El primero es parte de la declaración de principios realizada por MU el 30 de abril de 1977 en el entonces Boletín de la Campaña contra el Hambre. Se definía así la campaña:

“Es una acción mundial en la que participan un centenar de países distribuidos en todos los puntos de la tierra para luchar contra el hambre, la miseria, la falta de instrucción, la enfermedad, etc. Por la promoción del Hombre, por la Justicia y la Fraternidad...

12 La noticia está tomada del comunicado de prensa de la XXX Asamblea Plenaria del Episcopado Español, según se recoge en el Boletín Oficial de la Archidiócesis de Madrid-Alcalá (15 diciembre 1978) 835. 
No es una obra de ningún Gobierno ni de ningún partido político. No está inspirada por ningún país. No es tampoco una obra de la Iglesia. Es una movilización de todos los hombres de buena voluntad, para lograr que por todos los medios se termine con las plagas mencionadas y secree un mundo más humano, más justo, más de acuerdo con los designios de Dios"13.

Otro boletín de aquel mismo año (octubre 1977) describía así las actuaciones que estaba realizando MU:

\begin{abstract}
“A veces se cree que la Campaña contra el Hambre en el Mundo va dirigida sólo a los católicos por ser presidida por un Comité Católico. Ello no es así, pues va dirigida a todos los ciudadanos del mundo. Los trabajos de desarrollo que se promueven no tienen en cuenta la postura religiosa de quien los realiza, ni de quienes en países del Tercer Mundo participan en ellos. Aunque se piensa que las ONG no pueden hacer mucho por cambiar la situación del hambre y la injusticia, los proyectos de promoción (sanitarios, educacionales, agrarios, industriales y sociales) son un agente de cambio en muchas sociedades y un cauce de defensa de los derechos humanos. Además suponen un revulsivo en nuestra sociedad de consumo y una concienciación de cada miembro de nuestra civilización en una responsabilidad en cuanto a los otros pueblos de la Tierra"14.
\end{abstract}

Ambos testimonios, leídos sobre el trasfondo de la reciente crisis de MU, no dejan de ser muy significativos...

\title{
2.2. Manos Unidas y las otras ONGD españolas
}

Una vez contemplada brevemente la historia de MU, intentaremos situarla en el contexto de las ONGD españolas y detectar el papel que ahí ha desempeñado.

En los años ochenta apenas existía un puñado de ONGD en España que trabajaran en el campo de la Cooperación al Desarrollo. Entre otras razones, porque hasta esas fechas España había sido receptora neta de ayuda, dado su bajo nivel relativo de desarrollo. Fue en 1983 cuando, por iniciativa de la Comisión J usticia y Paz y con el fin de destinar el 0,7\% del PIB a la Ayuda Oficial al Desarrollo (AOD), se crea la Coordinadora de ONGD de España (CONGD E). Fueron socios fundadores: Ayuda en Acción, Cáritas Española, Consejo Interhospitalario de Cooperación, Intermón, Justicia y Paz, Medicus Mundi, Comisión 0,7\% y MU; también estuvieron presentes como miembros invitados Cruz Roja y UNICEF.

La CONGD E nació con un doble fin: actuar como interlocutor válido de las

13 I. de Felipe Boente (1981), loc. cit., p. 250.

14 I. de Felipe Boente, loc. cit. p. 271. 
ONGD ante las Administraciones Públicas; facilitar la colaboración entre las distintas ONGD en la realización de acciones comunes en el campo de los proyectos en el Sur y en la educación para el desarrollo.

MU participó activamente desde sus comienzos en la Coordinadora, donde desempeñó siempre un liderazgo difícil de exagerar. Así se entiende la presencia, desde sus inicios, de un miembro de MU en su Junta de Gobierno: Carmen de Miguel fue vicepresidenta de 1984 a 1990; Ana de Felipe de 1990 a 1994 y Luis Arancibia, presidente en 1995-98 y vocal de relaciones institucionales en 1998$2000^{15}$.

Y es que el peso de MU en la coordinadora ha sido, por distintas razones, siempre significativo: tiene 71 delegaciones distribuidas por todo el territorio nacional y es la única que está presente y activa en todas las coordinadoras autonómicas de ONGD; su financiación, de 7.193 millones de pesetas, representa el 9,5\% de los ingresos de las ONGD españolas; de ese volumen de recursos, y a diferencia de lo que suele ser normal, el 83\% son privados; cuenta con más de 4.500 miembros, de los que sólo 90 eran contratados (antes de la crisis). Es difícil comparar estas cifras con las tendencias medias de las ONGD españolas, dada la atomización y diversidad que existen entre ellas. En todo caso, MU ha venido siendo un referente para mostrar a las otras ONGD cómo crecer manteniendo la fidelidad al espíritu inicial con que fue creada.

\subsection{Algunos rasgos destacados de la evolución de Manos Unidas}

Analizaremos también la evolución que ha sufrido en el marco de los sucesivos enfoques que se ha dado a la Cooperación al Desarrollo y sus consecuencias sobre la educación para el desarrollo. Este último campo de acción es un indicador altamente significativo de la "filosofía" de toda ONGD. $Y$ en este terreno de la educación MU ha sido ciertamente pionera y ha servido de referente a otras muchas ONGD españolas.

Aquellos que, como observadores, hemos seguido la evolución de MU admiramos cómo evolucionó su concepción de la educación para el desarrollo: de ser una actuación puramente asistencial pasó a convertirse en un conjunto

15 Los cargos en la Coordinadora estatal y las distintas coordinadoras nunca han sido remunerados. Por lo tanto, y al margen de su relación contractual con $\mathrm{MU}$, estos cargos se asumieron con un talante de voluntariado aunque en ocasiones los designados por las ONGD para asumirlos fueron profesionales, como es el caso de Luis Arancibia. 
de actuaciones con el objetivo de "aumentar la conciencia y el compromiso de las personas para lograr un mundo más justo y más humano". Con ello se pretendía hacer frente a "los comportamientos individuales basados en valores y actitudes contrarios a la solidaridad", pero también al "compromiso y el comportamiento de las instituciones que conforman las estructuras injustas que generan pobreza y exclusión"16.

Este cambio de orientación supuso un arduo proceso interno, dado el respaldo social tan amplio con que contaba, tanto en los servicios centrales como en las distintas delegaciones: muy eficaces fueron los cursos de formación promovidos por los servicios centrales para las distintas delegaciones.

En el campo de educación formal para el desarrollo es, junto con INTERMON, pionera en la elaboración de materiales educativos que cubren las distintas etapas de la formación. Sus materiales son casi los únicos que de forma gratuita están presentes en la mayoría de las escuelas, colegios e institutos de España. A sabiendas de que esto no es suficiente y con la intención de que la educación para el desarrollo se incorporase en los textos escolares, ha venido colaborando habitualmente con algunas editoriales. En esta misma línea es una de las pocas ONGD que realiza cursos de formación homologados por el Ministerio de Educación. Por último, y con el ánimo de llegar a los niveles superiores de enseñanza, había firmado en estos últimos años convenios de colaboración con numerosas universidades (entre ellas: Málaga, Comillas, Salamanca y Granada).

Otra de sus líneas prioritarias en el terreno educativo es la sensibilización de la opinión pública. En este sentido fue pionera en diversos frentes: facilitando la formación y la información a los medios de comunicación a través de sus premios de prensa, radio y televisión; invitando a periodistas de distintos medios de comunicación a realizar viajes de seguimiento de proyectos junto a los miembros de MU con el fin de que descubrieran la realidad sobre el terreno y pudieran dar una visión más humana de las otras realidades del Sur; cofinanciando algunas series de televisión, como "Planeta Sur" en los ochenta, junto con otras ONGD y "Los excluidos", recientemente estrenada, magnífica serie sobre la realidad de los países del Sur. Instrumento esencial de sensibilización son sus boletines y folletos informativos, que se comenzaron a publicar en la segunda mitad de los noventa, de gran utilidad también para la formación en cooperación del amplio espectro de voluntarios.

16 MANOS UNIDAS (1999), op. cit. en nota 5, p. 9. 
Las acciones de presión política pueden considerarse como otra forma de sensibilización. Entre ellas destaca la actuación de MU en las campañas. Cabe mencionar en este ámbito la campaña "Adiós a las armas", más intensamente aún la campaña por la abolición de las minas antipersonales y, sobre todo, "Deuda externa ¿deuda eterna?", en la que MU ha sido el motor principal con actuaciones muy destacadas por todo el territorio nacional y con un éxito que es difícil ignorar. ${ }^{17}$ En este terreno político debe subrayarse también su participación, por elección del resto de las ONGD españolas, en el Consejo de Cooperación para el Desarrollo, órgano asesor y de participación del Ministerio de Asuntos Exteriores.

Esta forma nueva de entender la cooperación al desarrollo ha marcado también el tipo de proyectos financiados por MU. Cinco son las prioridades establecidas: promoción educativa, promoción social, promoción de la mujer, promoción sanitaria y promoción agrícola. En cambio, y en continuidad con sus orígenes, MU nunca financió proyectos pastorales, aspecto éste del que por cierto informaba habitualmente a sus donantes. Su relación con Ia Iglesia institucional era otra: por ejemplo, exigían siempre a sus contrapartes que fueran avaladas por el obispo de la región.

En ocasiones se ha criticado a MU la atomización de sus proyectos y el carácter asistencial de estos. En respuesta a estas críticas, aunque sin renunciar a sus orígenes, recientemente se estaba evolucionando tanto en el carácter de los proyectos (nuevas líneas: capacitación de líderes, microcrédi to...) , como en sus dimensiones (proyectos más amplios e integrados, más insertos en la realidad social) ${ }^{18}$.

\subsection{Voluntarios y profesionales en Manos Unidas}

Si en algo había llegado a ser un referente MU era en la convivencia en una misma organización de voluntarios y profesionales. Este es, sin duda, uno de los mayores problemas a los que deben hacer frente las ONGD españolas: la

17 El Gobierno y la jerarquía eclesiástica ejercieron una fuerte presión sobre las cuatro organizaciones católicas convocantes, para que no participasen en la consulta social sobre la deuda externa con ocasión de las elecciones generales de marzo pasado. Este conflicto pone también de relieve que hay un tipo de presencia pública de los cristianos que pueden no interesar ni a los gobiernos ni a la jerarquía.

18 Véase a este respecto la entrevista realizada a Bartolomé Burgos, "Hay que acabar con la cooperación del proyectito", Boletín de Manos Unidas no 140 (julio-septiembre 2000) 4-5.

\section{RFS}


incorporación de profesionales a su organización sin perder por ello los ideales y valores que inspiraron su creación.

En MU se produjo esta incorporación de profesionales desde finales de los ochenta y principios de los noventa. Por ejemplo, en el Comité Ejecutivo anterior a lasúltimas elecciones había 13 profesionales y 8 voluntarios, de loscuales una buena parte han dimitido a raíz de los últimos acontecimientos ${ }^{19}$. Nuestra relación con esta ONGD nos ha permitido descubrir, tanto a voluntarios con un talante verdaderamente profesional como a profesionales con talante voluntario por su disponibilidad de tiempo y de esfuerzos más allá de la simple relación contractual. Esto era posible porque todos compartían una misma fe y vocación de laicos comprometidos con el Evangelio.

En su carta de despedida, Consuelo Lobo, voluntaria desde 1989 y dimitida recientemente como presidenta, resumía su experiencia con estas palabras:

\begin{abstract}
“Durante estos años he intentado hacerlo lo mejor que entendía, pero debo reconocer que poco hubiera conseguido si no hubiera contado con la ayuda de todos aquellos que me apoyaron desde la fe y el desprendimiento personal y diario. He procurado trabajar en equipo con personas - muchas de ellas contratadas y altamente preparadas- cuyo principal objetivo es el servicio a los pobres. Vaya para ellas mi reconocimiento y admiración puesto que su comportamiento me parece que sería el que hoy podrían tener aquellos primeros cristianos que vendían sus bienes y los repartían cada cual según sus necesidades"20.
\end{abstract}

\title{
3. De los problemas explícitos a los interrogantes implícitos
}

La presentación del desarrollo de la crisis y de toda la historia de MU desde sus orígenes nos permitirá abordar por fin los problemas que se han ido planteando y tomar postura ante cada uno de ellos. Dichos problemas se manifiestan en forma diferente: unos se formulan explícitamente; otros subyacen a los debates. Son también de distinta índole: unos son de carácter más técnico, mientras que en otros están en juego cuestiones eclesiales y teológicas. Podemos sintetizarlos en cinco, que pasamos a analizar.

19 Pero no es este Comité Ejecutivo el principal órgano directivo de MU, sino el Comité Rector; así, por ejemplo quien tiene la última palabra para la aceptación de los proyectos, no es el Comité Ejecutivo sino el Comité Rector donde todos son voluntarios.

20 MANOS UNIDAS (2000). Boletín № 140 julio-septiembre, p. 3. 


\subsection{La presencia de profesionales en Manos Unidas}

Este es sin duda el asunto más técnico, en principio, de cuantos se debaten: la conveniencia de que haya profesionales de la cooperación en los cargos directivos de la organización.

Es preciso comenzar recordando que la Cooperación al Desarrollo ha venido a ser, cada vez más, un terreno complicado y difícil. En él no basta la buena voluntad; cada vez se hacen más indispensables la profesionalidad y la preparación en una serie de disciplinas científicas y sociales, si se quiere que - como suele decirse- "el remedio no sea peor que la enfermedad"21.

Nuestra experiencia directa de muchas ONGD nos permite afirmar que en ese complejo mundo de la Cooperación al Desarrollo lo que sobra precisamente es voluntarismo y lo que falta es más profesionalidad. Una mirada a la constelación de las ONGD importantes de la OCDE, y en particular a las de origen más o menos explícitamente cristiano, nos lleva a concluir que la presencia de profesionales contratados (con frecuencia de alto nivel) se ha hecho prácticamente imprescindible. Hoy se precisan conocimientos básicos de economía, de sociología, de técnicas para elaborar, realizar y evaluar proyectos, je marketing!, de contabilidad y gestión, de legislación, etc... para no cometer errores "de bulto" en el ya de por sí duro y difícil trabajo de la Cooperación al Desarrollo. Es cierto que todo cooperante -y más si es de inspiración cristiana como son todos los profesionales que tenía MU en su equipo directivo- necesita una buena dosis de misionero y un claro perfil de voluntario; pero necesita mucho más que eso, necesita preparación, mucha preparación, y dedicación, dedicación total (y por tanto retribución digna, aunque no sea cuantiosa, que le permita mantener a su familia). Esas características no pueden cumplirlas, salvo raras excepciones, los voluntarios normales.

Concretamente en el caso de MU pensamos que el número de profesionales que tenía contratados es adecuado a la dimensión que había alcanzado la organización. Casi paradigmático: porque ¿existen muchas organizaciones que puedan administrar un presupuesto de 7.200 millones de pesetas destinando tan sólo un 3,2\% a gastos administrativos? ¿Se podría haber realizado toda esta labor sólo con voluntarios? Creemos sinceramente que no.

El percibir una retribución económica no es incompatible en principio con el

21 Precisamente, entre otros similares, ETEA e Intermon han impartido en dos años consecutivos en Sevilla un master de formación en "Cooperación al Desarrollo y Gestión de ONGD".

\section{RFS}


más alto nivel de altruismo y desinterés evangélicos. Nadie cuestiona eso en el caso de los que asumen una responsabilidad eclesial ( párrocos, profesores de teología, muchas capellanías, clero castrense...). ¿Por qué dudarlo en el caso de algunos profesionales llamados a participar en los órganos directivos de MU?

No podemos negar algunas consecuencias problemáticas de esta, para nosotros, inevitable profesionalización. De hecho algunos han puesto en relación cierta pérdida de identidad cristiana con la presencia de los profesionales: "la profesionalización ha ido pareja a una cierta secularización y deseclesialización de la acción de algunas de estas organizaciones (...); se ha perdido el vínculo de la acción caritativa con las otras acciones eclesiales como la catequética, la litúrgica, ... con el conjunto de la comunidad cristiana" 22 . Pero ¿es necesario que las tareas de una institución tan especializada como MU tengan una conexión visible con esas otras acciones eclesiales? ¿No es igualmente problemática esta conexión en otras instancias de la Iglesia, como sería el caso de las universidades católicas o las revistas de teología? ¿Y duda alguien por ello de su sentido eclesial y evangelizador?

En todo caso la identidad cristiana de una institución no está en función de la proporción de voluntarios que trabajen en ella, ni la presencia de profesionales tiene por qué enturbiar el compromiso cristiano de la misma. Es más, ¿cuántas veces nuestra experiencia nos ha mostrado que el ser voluntario no garantiza el compromiso cristiano? ¿y a cuántos profesionales hemos conocido que viven su compromiso cristiano en profunda armonía con un alto nivel de competencia profesional? Como ha escrito Agustín Domingo Moratalla:

"La historia de la ética nos ha mostrado que ni la competencia es patrimonio exclusivo de los profesionales ni la buena voluntad es un monopolio de los voluntarios. Por eso, más que enfrentar a profesionales con voluntarios, una organización inteligente es aquella que promueve entre ambos una cultura de confianza y libertad, de lo contrario no sólo será una cueva para profesionales incompetentes, sino una madriguera para voluntarios de saldo"23.

Y si todo esto es cierto en el campo teórico, es preciso añadir que queda confirmado por la realidad de MU: podemos afirmar que ése es el modelo de profesionales al que responden los que nosotros hemos conocido en dicha institución.

22 En este caso, formuladas en unos comentarios poco afortunados, a nuestro juicio, de Carlos García de Andoin, en Vida Nueva, 5 de julio de 2000, p. 11.

23 "La identidad del voluntariado en Manos Unidas", Las Provincias, Valencia, 4 de agosto de 2000, y “El voluntariado en Manos Unidas, Vida Nueva, 29 de julio de 2000. 
Por otra parte, la resistencia a los profesionales puede ser también interpretada como un cierto miedo a su competencia, en el sentido de que el rigor, y hasta frialdad, de sus planteamientos se convierta en un obstáculo para la libertad de actuación de los que tienen la última responsabilidad de una institución. Pero entonces ya el conflicto no es entre profesionales y voluntarios, sino profesionales y responsables últimos. Este conflicto no hay por qué excluirlo: se presentará cuando las últimas razones de una decisión no son estrictamente técnicas. Ahora bien, este no puede ser el caso normal; y cuando llega, el debate será fecundo siempre que exista flexibilidad en cada parte para comprender la lógica de la otra. Más vale la tensión entre ellas, que eliminar una de las dos para evitar los problemas.

\subsection{El destino de los recursos económicos}

Como ya dijimos, la otra razón del conflicto, ha sido la negativa de MU, durante las presidencias de Ana de Felipe y de Consuelo Lobo, a dedicar parte de sus fondos a acciones directamente pastorales confesionales católicas. También esta cuestión puede ser abordada desde un punto de vista preferentemente técnico 0 , si se quiere, estratégico.

Un criterio decisivo sería aquí la voluntad de los donantes. Es evidente que MU recauda y administra cantidades importantes de recursos. Su historial y el respaldo de la Iglesia institucional son una garantía para el que da. Una parte cuantiosa de la recaudación procede de las colectas que se hacen en todos los templos de España con ocasión de la Campaña del Hambre. Pero cada vez se incrementan más los recursos procedentes de personas no vinculadas a la Iglesia. Y más importantes son todavía los que llegan de instituciones públicas (municipales, autonómicas, estatales o europeas): porque hoy la Ayuda Oficial al Desarrollo canaliza cantidades crecientes de sus fondos a través de las ONGD que les merecen más crédito. Y entre ellas está, sin duda, MU.

Ante esta diversidad de fuentes surgen algunas preguntas. ¿Estarían algunos donantes privados y las instituciones públicas de acuerdo con este destino "confesional" ( por así decirlo) de los fondos? ¿No es más coherente dedicarlos a acciones humanitarias, de lucha contra la pobreza, de educación para el desarrollo, etc., que a proyectos estrictamente pastorales? Por lo que respecta a los creyentes colaboradores, ¿tienen dificultad en que sus ayudas se dediquen a este tipo de proyectos humanitarios, que ha sido por otra parte lo tradicional de MU? 
Una solución podría consistir en dividir MU en dos, para destinar así una parte de sus fondos a actividades directamente pastorales. Pero ¿no debilitaría eso a la organización de modo decisivo? ¿no empañaría su imagen pública? ¿no existen ya otras agencias eclesiales que realizan colectas específicas para estos objetivos más pastorales (las Obras Misionales Pontificias y la tradicional colecta del Domund) ? ${ }^{24}$

En todo caso, es motivo de sano orgullo el ver cómo una notable proporción de los proyectos de MU se encauzan a través de instituciones religiosas mayoritariamente católicas insertas en los países de destino que, por su honestidad y fiabilidad, ofrecen la máxima garantía de buena utilización de los recursos según los fines para los que fueron recaudados. Y los que dan movidos por su fe comprenden que estos proyectos no directamente pastorales constituyen un apoyo fundamental a la acción misionera evangelizadora propiamente dicha. Pero es aquí donde radica el problema que nos parece de más alcance en todo esto: ¿es coherente con el carácter eclesial de MU dedicar tantas energías y tantos recursos a tareas tan profanas?

\subsection{Los fines de Manos Unidas como institución de la Iglesia}

Aquí está, en nuestra opinión, el nudo gordiano de todo este debate. Todos los demás aspectos que aquí se discuten casi son consecuencias de esto.

Concretamente se ha acusado a MU de que su acción benéfica es ambigua en cuanto a su "confesionalidad" católica, que no es suficientemente "evangelizadora" en sentido explícito, o, dicho de otra forma, que no se ocupa de fomentar la pastoral directa en los territorios de misiones en la medida que sería deseable. En concreto, partiendo de esa acusación de ambigüedad, se exige a la organización una "necesaria clarificación teológica y eclesial" 25.

24 Son muchas las instituciones religiosas (congregaciones misioneras, sobre todo) que recaudan fondos mediante "procuras de misión" o entidades similares, cuyo destino es indistintamente la ayuda a la evangelización directa y el sostenimiento de instituciones de caridad y de desarrollo entre las poblaciones de los Ilamados "territorios de misión". Es la pluralidad versátil subyacente a toda la acción del cristiano en el mundo.

25 Por tratarse de una persona muy significativa en el mundo eclesial y teológico de nuestro país, son especialmente significativas algunas valoraciones vertidas por Olegario González de Cardedal, catedrático de Teología de la Universidad Pontificia de Salamanca, en alguno de sus escritos, que han contribuido a sembrar la sospecha y a alimentar la crítica sobre MU. En un contexto en el que se refiere a la necesidad que tiene la Iglesia de afirmar su "radicalidad evangélica", evitando (y es muy fuerte lo que dice) la "degradación interna de su fe dogmática 
Esta clarificación debería partir, según nuestro punto de vista, de la siguiente pregunta: ¿se justifica que las tareas de una institución de la Iglesia sean sólo de promoción humana (iy nada menos que eso!), sin que aparezca en ellas directamente la dimensión evangelizadora?

El tema no es nuevo. El ejercicio de la caridad con los necesitados constituye una tradición que se remonta a los orígenes mismos de la Iglesia. Y no sólo como iniciativas de los creyentes en cuanto personas particulares, sino como tarea de la institución eclesial en cuanto tal. La atención a los pobres menesterosos fue durante siglos responsabilidad de la Iglesia, y así le fue reconocido en la organización de la sociedad.

Sólo en la época moderna esta actividad de beneficencia fue siendo asumida por los poderes públicos, y por cierto no sin airadas quejas y dura resistencia por parte de la Iglesia, que consideraba que las autoridades seculares estaban invadiendo un terreno que era de su exclusiva competencia.

Hoy no tendría sentido seguir reivindicando esta exclusividad. Más bien hay que felicitarse de que, al menos en determinadas sociedades, el objetivo de una mejor distribución de la riqueza haya sido asumido por toda la sociedad a través de instituciones públicas. ¿Qué lugar queda entonces a la Iglesia?

Desde mediados del siglo XX han sido muchos los cristianos y las iglesias particulares que han sentido una fuerte llamada a luchar por la justicia en aquellas regiones del mundo donde las desi gualdades eran más flagrantes. Eran esos años-los 60- en que se generalizaba la conciencia de que el subdesarrollo del tercer mundo se convertía en destino casi inevitable para inmensas mayorías humanas.

\footnotetext{
y de su fidelidad moral", ilustra su pensamiento con dos ejemplos, uno de los cuales es precisamente MU. Aunque remitimos al lector al texto completo, para no alargar la cita, el teólogo se refiere textualmente a la dificultad que encuentran este tipo de "instituciones cristianas a realizarse como tales"... Y añade: "si de manera permanente se excluyen esos proyectos [específicamente pastorales] y la referencia a la Iglesia, tal como de hecho ella es, y se la difumina en sus programas, entonces se comprende que surjan recelos y distancias; que las diócesis dejen de sentirse obligadas a proponer las colectas parroquiales como cauce para tal fin, dado que una latente ambigüedad en manifestaciones y acciones no permite percibirlas como acción específica de la Iglesia. Si los fines ya no están claros, entonces las autoridades de la Iglesia se preguntan por la obligatoriedad moral de colaborar... apareció un problema de fondo: la necesaria clarificación teológica y eclesial". Cf. O. González DE CARDEDAL, "Reflexión final. Cristianismo, Iglesia y sociedad en España: 1950-2000", en: O. GonzáLEZ DE CARDEDAL (ed.), La Iglesia en España 1950-2000. PPC, Madrid, 1999, 374-375. Las cursivas son nuestras.
} 
Esta sensibilidad, nacida en situaciones nuevas y apoyada por un análisis distinto de estos problemas y de la acción social en general, no sólo dio pie a innumerables esfuerzos de muchos cristianos anónimos, sino que tuvo también su reflejo en el concilio Vaticano II y en toda la teología que se elaboró en los fecundos años que le siguieron.

La cuestión surgía desde una doble preocupación: por una parte, se pretendía purificar la praxis de los siglos pasados (excesivamente volcada a paliar los efectos de las injusticias, y menos atenta a combatir las causas de las mismas) y adaptarla mejor a los nuevos datos de las ciencias sociales; por otra, se buscaba un lugar más adecuado para la inserción de la Iglesia en la sociedad moderna, tan secular como opulenta y discriminatoria.

En un afán por reducirnos a los hitos más significativos de este proceso de reflexión, vamos a citar tres momentos, tal como se han reflejado en documentos oficiales de la Iglesia:

1ㅇ) El Vaticano II definió a la Iglesia así:

"La Iglesia es en Cristo como un sacramento o señal e instrumento de la unión íntima con Dios y de la unidad del género humano" (Concilio Vaticano II, Constitución Dogmática sobre la Iglesia Lumen gentium, 1).

Tras la solemnidad y concisión de este texto se esconde toda una panorámica de acción para la Iglesia y para cada uno de sus miembros: su misión es hacer realidad ("signo e instrumento") esa doble aspiración humana, la apertura a la trascendencia y la fraternidad de todos. Y este es un anuncio que se hace, no sólo con las palabras, sino con la vida, es decir, a través del compromiso de sus miembros (por eso es "signo e instrumento", y no mero heraldo o portavoz).

2ㅇ) Esta manera de entender la Iglesia se proyectó unos años más tarde, justamente cuando más aguda se va haciendo la conciencia de las injusticias mundiales, sobre el esfuerzo de muchos cristianos por empeñarse en la lucha contra ellas. Fue el sínodo universal de 1971, máxima autoridad colegial de la Iglesia entre concilios, el que afirmó:

"La acción en favor de la justicia y la participación en la transformación del mundo
se presenta claramente como una dimensión constitutiva de la predicación del
evangelio, es decir, de la misión de la Iglesia para la redención del género humano
y la liberación de toda situación opresiva" (SinODo UNIVERSAL DE OBISPOS DE 1971, La
justicia en el mundo, Introducción).

El texto no se anda con rodeos: afirma rotundamente que comprometerse en la transformación de la sociedad pertenece a la misión de la Iglesia de evangelizar. No es una consecuencia, sino una "dimensión constitutiva". No se 
evangeliza para luego transformar la realidad, sino que esta transformación social es ya evangelización, aunque no es toda la evangelización (es "una" dimensión constitutiva).

3o) El peligro de reducir la misión de la Iglesia a pura tarea de cambio social ( tan real en aquellos tiempos para muchos cristianos, urgidos por la experiencia de la injusticia) llevó al sínodo universal de 1974 a estudiar más a fondo la relación de estas tareas de promoción humana con la evangelización y con la Iglesia misma. Pablo VI, recogiendo un año después los frutos de aquella asamblea, lo formularía así:

\begin{abstract}
"La evangelización, hemos dicho, es un proceso complejo, con elementos variados: renovación de la humanidad, testimonio, anuncio explícito, adhesión del corazón, entrada en la comunidad, acogida de los signos, iniciativas de apostolado" (PABLO VI, Evangelii nuntiandi, 24).
\end{abstract}

La tarea de promoción humana es, como ya dijera el sínodo anterior, parte de la evangelización. Pero Pablo VI añade ahora que ésta es un proceso complejo, y no un acto puntual. Ese proceso incluye momentos sucesivos: y entre ellos -y nótese el orden en que se colocan- la renovación de la humanidad y el testimonio preceden al anuncio explícito del mensaje, el cual había sido tenido tradicionalmente por lo esencial de la evangelización.

Luchar por un mundo más justo es abrir el camino de la evangelización, es ya evangelizar, porque es hacer ya realidad-aunque de forma incipiente y germinal- esa fraternidad a que aspira el corazón humano. En la dinámica de todo el proceso evangelizador se implica toda Ia Iglesia, aunque no todos sus miembros e instituciones están presentes de la misma manera en cada una de sus fases. La tarea de evangelizar es de toda la Iglesia y cada uno participa en ella con conciencia de contribuir a algo que sólo se completa entre todos.

Con sólo estos elementos es fácil encontrar justificación a lo que ha venido haciendo tradicionalmente MU, aun cuando nunca llegue a ocuparse de lo expresamente pastoral. Porque MU no lo es todo en la Iglesia, ni pretende que en esas acciones a que se ha venido dedicando hace tiempo está el todo de la evangelización. La colaboración con otros sectores o instancias de la Iglesia le ayudaría, sin duda, a tomar más conciencia de que su actividad también es evangelizadora, e incluso a visibilizarlo mejor.

Eso no obsta para que destine algunos fondos a proyectos más directamente pastorales. Pero no tendría que llegar ahí para encontrar pleno sentido eclesial a su actividad. Si financia ese tipo de acciones será por otros motivos, ya sea por la urgencia de ciertas situaciones, ya por oportunidad estratégica.

\title{
RFS
}


Un paso más. En todo esto la Iglesia no está innovando o rompiendo con su tradición. Ya lo vimos al recordar su trayectoria en tareas asistenciales, cuando nadie apenas se ocupaba de ellas. Pero podemos decir que la Iglesia del siglo XX ha sido impulsada en este cambio de rumbo por una vuelta a sus mismas raíces. Como decía el sínodo de 1971, ya citado, sintetizando lúcidamente continuidad y renovación:

“La situación actual del mundo vista a la luz de la fe nos invita a volver al núcleo mismo del mensaje cristiano creando en nosotros la íntima conciencia de su verdadero sentido y de sus urgentes exigencias" (Sínodo UniverSAL DE OBISPOS DE 1971, La justicia en el mundo, Parte II, n. 1).

Ahondando en estas raíces más lejanas inmediatamente se nos vienen a la memoria los textos de los profetas, que tanto fustigan una religión entendida como un culto a Dios que se olvida de la justicia interhumana: porque la relación con Dios carece de sentido y queda vacía de contenido si coexiste con la injusticia que se ceba en los más débiles de la sociedad.

Sin remontarse tan lejos, muchos cristianos implicados en tareas de promoción humana se habrán sentido impulsados y estimulados por textos evangélicos como la parábola del buen samaritano ( LC 10, 29-37) o la escena del juicio final (Mt 25, 31-46). El contenido de una y otra deja poco lugar a dudas...

¿Cabría criticar al buen samaritano porque su acción no fue más explícitamente evangelizadora? ¿Puede ser calificada esa actitud de ambigua por no mencionar a su Dios ni buscar proselitismo alguno con un gesto que nace estrictamente de la "compasión"? ¿Hay que plantearse siquiera si el herido percibió la acción solidaria del samaritano como "acción específicamente religiosa"? ¿No habría que dejarse llevar más bien por esa praxis samaritana, por eso que algunos Ilaman la "cultura samaritana"? ${ }^{26}$

Algo parecido ocurre con la escena del juicio final. Si algo queda bien subrayado en ella es el desconocimiento de los bienaventurados acerca del destinatario último de su acción caritativa: el propio Jesús. Han hecho el bien "...sin mirar a quién", y precisamente por ello reciben la alabanza del Maestro y son llamados al premio definitivo.

Ambos textos son suficientemente elocuentes como para no tachar a la acción caritativa de la Iglesia en general ${ }^{27}$, y de MU en particular, de falta de

26 Ha reflexionado profundamente sobre el tema: R. Díaz Salazar (1998), La izquierda y el cristianismo, Ed. Taurus, cf. sobre todo págs. 396 ss.

27 Un conflicto no muy diferente al que comentamos afectó no hace mucho tiempo a Cáritas, la 
claridad en sus fines. Lo contrario ¿no sería corregirle la teología al propio Maestro?

Es más, si volvemos de nuevo a nuestro tiempo, ¿no se hace hoy más necesario atender a lo que podríamos llamar un "cristianismo de frontera"? Ese terreno no está exento de riesgos, pero eso nunca debería ser razón para huir de él. ¿No existe hoy en la Iglesia un ansía excesiva de seguridad y de límites doctrinales precisos, un miedo a la "contaminación mundana" que podría esterilizar muchas iniciativas pastorales? Quizás el riesgo de la frontera -con la debida sabiduría, jclaro!- es uno de los grandes retos de la Iglesia de hoy.

En conclusión, no parece haber incoherencia alguna -sobre todo, si atendemos a las características de la sociedad de hoy- en una institución de Iglesia cuyas tareas son sólo de promoción humana, sin que aparezca en ellas directamente la dimensión evangelizadora. Porque eso ya es anunciar a J esús, y porque este anuncio hoy tiene que optar por vías más indirectas antes de hacerse más explícito e inequívoco.

De acuerdo con este planteamiento y sin mostrar dificultad alguna en él, la reciente Guía de la Iglesia Católica en España hace esta sintomática observación al presentar a MU:

\begin{abstract}
"Aun cuando Manos Unidas es una organización de seglares confesional, las acciones y fines que se propone son exclusivamente humanitarias, no discriminando en modo alguno a nadie que pueda ser beneficiario de ellas por razón de su sexo, raza, religión, etc." 28 .
\end{abstract}

\title{
3.4. La forma de inserción de Manos Unidas en la Iglesia española
}

Una cuestión ulterior es la de la fórmula jurídica de MU en cuanto institución eclesial. Ya dijimos que poseía personalidad jurídica canónica desde 1978. Pero en el nuevo Código de Derecho Canónico, promulgado en enero de 1983, se aquilató más el carácter de las asociaciones eclesiales. Para ello se recurrió a la distinción entre asociaciones públicas y asociaciones privadas. Todas las asociaciones que ya existían en aquel momento tuvieron que redefinirse para adoptar una de las dos formas. Determinar qué modelo era el más adecuado en cada caso no fue fácil para todas las asociaciones, lo que ha dado lugar a

importante organización caritativa oficial de la Iglesia Católica con resultados por desgracia semejantes.

28 Oficina de Estadistica y Sociología de la Iglesia, loc. cit. en nota 6.

\section{RFS}


algunas situaciones embarazosas en el transcurso de estos años. MU adoptó finalmente la fórmula de asociación pública de la Iglesia.

Unas nociones sobre las características de cada uno de los dos modelos ayudará a clarificar desde otra perspectiva el reciente conflicto de MU.

Las asociaciones privadas responden al derecho de asociarse libremente, reconocido también a los cristianos en la Iglesia. Son creadas por un acuerdo privado entre ellos. Las asociaciones públicas, en cambio, son erigidas por la autoridad eclesiástica. Aunque ambas están sometidas a una vigilancia última por parte de dicha autoridad, las públicas tienen un mayor control: los estatutos deben ser aprobados por dicha autoridad y sus dirigentes nombrados por ella. Además la erección les confiere personalidad jurídica canónica, mientras que las privadas sólo pueden conseguir ese status por un decreto expreso de la jerarquía y una vez que ésta ha aprobado sus estatutos. En España, además, ambas pueden adquirir ulteriormente la personalidad jurídica civil con la sola inscripción en el Registro de Entidades Religiosas del Ministerio de Justicia.

Hasta aquí los rasgos más específicos de unas y otras. Pero la cuestión más delicada es la de los criterios que determinan si una a sociación eclesial debe ser pública o privada, sobre todo si ya existía antes de la promulgación del actual Código ( caso de MU). El mismo Código indica cuáles son las asociaciones que, en principio, deben ser públicas. Y lo hace en dos pasos: en un primer caso estamos ante una responsabilidad propia de la jerarquía, mientras que el segundo se trata de una intervención de carácter subsidiario. Veamos cómo se formula en el art. 301:

1. Corresponde exclusi vamente a la autoridad eclesiástica competente erigir asociaciones de fieles que se propongan trasmitir la doctrina cristiana en nombre de la Iglesia, o promover el culto público, o que persigan otros fines reservados por su misma naturaleza a la autoridad eclesiástica.

2. Si lo considera conveniente, la autoridad eclesiástica puede erigir también asociaciones que directa 0 indirectamente busquen otros fines espirituales, a los que no se provea de manera suficiente con la iniciativa privada.

Naturalmente MU estaría entre las asociaciones contempladas en este segundo supuesto, las creadas por intervención subsidiaria de la jerarquía. ¿Por qué se optó en su momento por darle el carácter de pública? ¿Tal vez por hacer de ella el instrumento de la presencia oficial e institucional de la Iglesia española en el campo de la Cooperación al Desarrollo? ¿Es esto coherente con el artículo citado, que sólo en caso de que "no se provea de manera suficiente 
con la iniciativa privada" aconseja a la autoridad eclesiástica actuar?

En todo caso, el actual estatuto de asociación pública de MU tiene consecuencias indiscutibles para su funcionamiento. Dos concretamente han sido en estos meses motivo de debate:

a) La aprobación de los nuevos estatutos. La modificación de los estatutos tiene que contar con la aprobación de la autoridad eclesiástica. Cuestión diferente es la de las formas como se ha procedido, que, por los datos que tenemos y se han recogido más arriba, no deja en buen lugar a la jerarquía...

b) El nombramiento de los dirigentes ( presidente nacional, en este caso). A la autoridad eclesiástica compete la "confirmación" de los dirigentes elegidos en la asociación. Por lo que sabemos, la Conferencia Episcopal Española ha venido exigiendo que las asociaciones presenten una terna de candidatos con objeto de no restringirle tanto sus márgenes de actuación. En el caso que nos ocupa se ha optado por otra vía: probablemente para evitar un eventual rechazo del candidato elegido por la asamblea los obispos vetaron previamente a varias de las candidatas propuestas. Actuar así supone, por lo menos, una interpretación restrictiva de la normativa vigente. No es posible eludir las preguntas: ¿fue esa la forma más adecuada de intervenir? ¿se respetaba así suficientemente la iniciativa de un colectivo tan acreditado como MU? ¿existían razones de peso, nunca comunicadas que sepamos, para actuar así?

En conclusión, tendríamos que interrogarnos si la asociación pública sea el estatuto jurídico más adecuado para MU, dada su trayectoria en las cuatro décadas de existencia. Pero nos duelen los procedimientos escogidos para ejercer unos derechos, que la Conferencia Episcopal poseía, no sólo en virtud de los estatutos vigentes, sino como expresión del derecho y el deber de los obispos a ejercer sus responsabilidades pastorales sobre cualquier institución eclesial. Estos procedimientos no han estado a la altura de lo que creemos deben ser unas relaciones de confianza y transparencia en la comunidad eclesial. Y esto nos sitúa a las puertas del último de los problemas que queríamos abordar.

\subsection{La concepción subyacente del laicado y de su puesto en la Iglesia}

En efecto, lo que subyace últimamente a los distintos aspectos de este debate es el reconocimiento de los laicos en la Iglesia, y especialmente por parte de la jerarquía de ésta. El problema nos remite de nuevo al concilio Vaticano II, que

\section{RFS}


abordó la superación de las ideas preconciliares sobre los laicos en el marco de la actualización que él mismo hizo de la doctrina sobre la misión de la Iglesia (cf. supra 3.3).

El Vaticano II fue el concilio de los laicos. Tras siglos en que la teología y la praxis eclesial habían potenciado el papel del sacerdote, las nuevas ideas del Concilio permitían poner término a esta larga etapa de clericalización de la Iglesia.

La teología preconciliar entendía el lugar de los laicos en la Iglesia según el modelo de delegación y participación en el apostolado jerárquico. La realización más acabada de este modelo fue la Acción Católica (según la mentalidad que le impuso Pío XI). Según esa concepción, los verdaderos protagonistas de la misión de la Iglesia eran los miembros de la jerarquía, pero ésta se ayudaba en su tarea de los laicos, que participaban por delegación de acuerdo con el mandato que recibían. Aunque más tarde se suavizaría esta fórmula con el recurso al término "colaboración", se seguía manteniendo la idea de un mandato que los laicos recibían de sus pastores.

El Concilio reconsideró la identidad del laico en la Iglesia desde la forma de entender la misión de ésta, según vimos más arriba. La misión es tarea de todo creyente, independientemente del lugar que ocupe en la comunidad eclesial. La dimensión profética de la misión también compete a los laicos, llamados por esta razón a "juzgar con más precisión y objetividad tanto los asuntos temporales como espirituales" (Constitución Lumen gentium, 37). Esta autonomía que se reconocía a los laicos abría enormes perspectivas a su presencia evangelizadora en el mundo, al tiempo que obligaba a precisar ciertos matices. Así el mismo Concilio reconocía la pluralidad de opciones dentro de la Iglesia, sobre todo en las cuestiones sociales, políticas y económicas. Ello aconsejaba distinguir entre actuaciones de los cristianos o de las organizaciones compuestas por ellos como cristianos y aquéllas otras que se hacían en nombre de la Iglesia en cuanto institución jerárquicamente constituida. Así se reforzaba la posibilidad del pluralismo, al tiempo que se obviaba la necesidad perentoria de una mediación jerárquica para actuar como cristianos.

Toda esta profunda revisión doctrinal debía ser puesta en práctica ulteriormente. Y los problemas no faltaron. Es más fácil moverse en el terreno de las ideas que sacar las consecuencias de éstas para la vida de cada día. Las décadas que siguieron al Concilio estuvieron marcadas por estos conflictos. Dos fueron los más relevantes. El primero se produjo en España a final de los años sesenta, cuando las ramas especializadas de la Acción Católica, entonces tan pujantes 
y estimuladas por el reciente Concilio, no llegaron a entenderse con los que estaban entonces a la cabeza de la Conferencia Episcopal Española (Mons. Morcillo y Mons. Guerra Campos) : el resulta do fue la crisis de estos movimientos apostólicos, que prácticamente desaparecieron o perdieron una gran parte de sus miembros. En los años 80 una nueva crisis se desencadenó en Francia, Alemania e Italia. Ahora se enfrentaban los que defendían la presencia institucional de la Iglesia en la sociedad, con asociaciones específicamente católicas y que actuaban como tales, y los que propugnaban la colaboración de cristianos y no creyentes en movimientos concordes con los valores evangélicos. El debate sigue hoy en pie, pero ya entonces esta segunda crisis debilitó aún más a las asociaciones laicales y dividió al laicado en los distintos países.

Este recuerdo de hechos tan recientes nos hace temer que el conflicto actual de MU pueda saldarse con un precio tan alto como el de entonces: el deterioro o desmantelamiento de una asociación (como ocurrió entonces), el debilitamiento de la acción social de la Iglesia y de su presencia en el mundo (y precisamente en relación con una institución que se había ganado una notable credibilidad en ambientes seculares).

¿Se repetirá la historia? MU es -en palabras del Secretario de la Conferencia Episcopal Española- una organización "muy fiable", que destaca por su eficiencia en llevar recursos a los necesitados y por sus bajos costos de gestión, publicidad y administración. ¿No es todo eso suficiente para reconocerla y apoyarla como iniciativa laical dentro del pluralismo de opciones que el Vaticano II reconoció hace ya 35 años? ¿Tienen derecho los laicos a una pluralidad de mediaciones eclesiales? ¿Vamos a volver a los tiempos en que la única mediación en lo temporal sea la que determina la jerarquía?

\section{Conclusión}

Al término de este largo recorrido reafirmamos el deseo que nos ha movido en toda esta reflexión: contribuir a un debate que ha crispado al gunos a mbientes eclesiales y ha acabado saltando, como era inevitable, a los medios de comunicación.

Nuestra preocupación no es sólo de imagen. Pero no despreciamos este aspecto, por las repercusiones que tiene para la acción de la Iglesia y de los cristianos en una sociedad secular y menos receptiva a cualquier mensaje auténticamente religioso.

La cooperación al desarrollo ha sido un campo en que la Iglesia y muchas de

\section{RFS}


sus organizaciones han sido pioneras, contribuyendo no sólo a reducir los niveles de inhumanidad de nuestro mundo, sino también a preparar el terreno para una tarea explícitamente evangelizadora. Y MU ha desempañado un papel decisivo en todo ello.

Sería lamentable que este conflicto afectara irreversiblemente la viabilidad de lo que se ha ido edificando en tantos años de búsqueda y compromiso.

No somos optimistas. Y no nos cuesta reconocerlo. No encontramos en las tendencias dominantes en la jerarquía actual de la Iglesia la sensibilidad que estos temas tan complejos requeri rían. Nos parece que sus preocupaciones van por otra línea.

Pero no queremos renunciar a la esperanza de que el diálogo llegue a reinstaurarse por parte de todos. Deseamos que no se imponga la dialéctica de vencedores y vencidos ni se "haga leña del árbol caído". El recuerdo de Juan XXIII, recientemente beatificado y propuesto como modelo a la Iglesia, sirva como invitación para la única salida humanamente viable y cristianamente justificable: un diálogo fraterno y un discernimiento dócil al Espíritu. 